\title{
Descriptive account of long-term health and behavior of two satellite-tagged captive harbor seals Phoca vitulina
}

\author{
Lisa M. Mazzaro, J. Lawrence Dunn* \\ Mystic Aquarium \& Institute for Exploration, 55 Coogan Blvd. Mystic, Connecticut 06355, USA
}

\begin{abstract}
The use of satellite tags to monitor pinnipeds in their natural habitats has become a common practice. However, near-continuous long-term observations of the behavior of tagged animals, the process of tag detachment, and regular close examination of the tagging site to detect any development of tag-induced lesions have not been reported. The present study investigated these issues. Dummy satellite tags were glued to two captive male Pacific harbor seals Phoca vitulina richardsi using mesh or no mesh attachment. Tag attachment and animal health and behavior were monitored during the $8 \mathrm{mo}$ attachment period. No tag-associated changes in animal health or behavior were noted until the tags started to loosen a few days before detachment. We found no differences in the strength or length of attachment associated with mesh or no mesh attachment. There was a small area of superficial skin irritation associated with the mesh attachment due to cracked epoxy rubbing against the seal. Although this was a small pilot study, we concluded that the satellite tag attachment and detachment processes were without significant adverse effect, that the tagged seals behavior was not significantly altered, and that it is likely that these findings will hold true for other small phocid seals.
\end{abstract}

KEY WORDS: Harbor seal $\cdot$ Phoca vitulina $\cdot$ Satellite tags

Resale or republication not permitted without written consent of the publisher

\section{INTRODUCTION}

Satellite tags are frequently used to study pinnipeds in their natural environment, relocate individuals for serial sampling, and track healthy animals released after rehabilitation (Harvey 1991, Folkow et al. 1996, Lowry et al. 1998, Burns et al. 1999, Early et al. 1999, Jay \& Garner 2002, Matthiopoulos et al. 2004). In most studies, once a tag is attached to an animal, the animal is released and after this point there is little that can be done to monitor for the presence of skin irritation, or to determine how and when the tag detaches from the body. While some studies (e.g. Baker \& Johanos 2002) have investigated differences in body condition in resighted experimentally tagged versus control animals, many researchers have operated under the assumptions that the tag: (1) falls off at the next molt, (2) is not bothersome and has little or no effect on natural behavior, and (3) does not cause any adverse affect on the health of the animal such as skin irritation at the attachment site. Recently, McMahon et al. (2008) reported that tagging devices attached to elephant seals of all ages and sizes did not affect individual mass gain or survival. They obtained data from a large number of seals upon arrival on the beach before and after tag placement but were unable to visually monitor the tagged animals during their time at sea. As there is virtually no literature describing continuous long-term visual and behavioral monitoring of tagged individuals, a pilot study was performed in a controlled setting using 2 captive Pacific harbor seals Phoca vitulina richardsi to which dummy tags were attached using the 2 methods described below. Information on effects on the skin, pelage, and behavior of animals outfitted with long-term satellite tags is especially important to assure the humaneness of the attachment and detachment processes and to ensure that the behavior of the tagged animal, and hence the data collected, has not 
been unduly affected by the presence of the tag. The present descriptive study examines the effect of 2 types of satellite tag attachment on animal behavior and health. Our small sample size precluded a proper statistical evaluation of the data.

\section{MATERIALS AND METHODS}

Two captive-born, young adult male harbor seals (ages 4 and 7 yr) were used for the present study. Both animals were housed at Mystic Aquarium \& Institute for Exploration in a 120000 gallon (454000 1) habitat containing a dilute brine solution (30 ppt) with 2 other harbor seals and a varying number of northern fur seals Callorhinus ursinus and Steller sea lions Eumetopias jubatus throughout the 8 mo study. The water is continuously filtered but there is no man-made wave action present. The west-facing exhibit contains a beach with large rocks, a small cave area, a shallow rocky tide pool, and 2 rocky pedestal haul-out areas.

Dummy satellite tags donated by Wildlife Computers having the same dimensions and weight $(8 \times 4.5 \times 3 \mathrm{~cm})$ as Spot2 tags used previously, but minus the electronics and the antenna, were employed. Although an antenna has the potential to effect tag attachment and behavior because of contact with the environment or other animals, we eliminated the antenna to avoid the possibility of injury to some visually impaired animals in the exhibit. One day before tagging the subject animals were removed from the exhibit and transferred to a holding area to allow their coats to thoroughly dry. An intravenous dose of diazepam (15 mg IV for the $60 \mathrm{~kg}$ animal, and an initial $20 \mathrm{mg}$ IV followed by an additional 5 mg IV $10 \mathrm{~min}$ later for the $93 \mathrm{~kg}$ animal) was given to each animal approximately $30 \mathrm{~min}$ prior to tag placement to achieve light sedation. Each subject was moved into a squeeze cage that provided access to the tag placement site. The restraint time for each animal was less than $30 \mathrm{~min}$. The seals were monitored continuously by a veterinarian during the procedure. Husbandry staff provided the minimal additional manual restraint needed during tag placement.

Dummy tags were prepared for attachment in the same manner as employed for operational tag placements. The attachment surface on each tag was scored with rough sand paper and then cleaned with an acetone-soaked towel. An approximate $5 \times 10 \mathrm{~cm}$ attachment area, centered on the dorsal midline of each animal just posterior to the skull, was cleaned with acetone. A 5-minute epoxy (Devcon ${ }^{\circledR}$ polystrate ${ }^{\mathrm{TM}}$ ) was used to attach the tags. Although the epoxy mixture was exothermic, at no time was the mixture so warm that the persons mixing it had difficulty comfortably holding the small plastic weigh boat, used as a mixing container, in the palm of their ungloved hands, nor was there any observed reaction to the application of the epoxy by the animal. Tag attachment was the same for both seals except that the tag attached to one animal had an oval-shaped $10 \times 15 \mathrm{~cm}$ flexible fiberglass mesh layer $(1 \times 2 \mathrm{~mm})$ placed between the pelage and the tag. Epoxy was first placed on the pelage in a rectangular patch making sure to penetrate it well. The mesh was placed on the pelage with some hairs penetrating the mesh and additional epoxy was used to make certain that the edges of the mesh were securely tacked down. This method of attachment ensured that a number of hairs would penetrate the mesh and, combined with the increased surface area of the mesh, potentially provide improved attachment. Finally, epoxy was applied to the bottom surface of the tag and it was placed and held firmly on the mesh or on the cleaned coat of the non-mesh subject. More epoxy was applied to the sides of the tag where they met the body surface or mesh so that there was a continuous seal between the pelage and the bottom margins of the tag. The animals were restrained until the epoxy cured. Following the procedure the animals were released to a dry holding area and then returned to their exhibit the afternoon of the following day.

Animal health, food consumption, body mass, behavior, tag attachment, skin condition, and tag stability were monitored throughout the 8 mo of the study by husbandry and veterinary staff familiar with the norms for these 2 animals. The animals were desensitized to contact with trainers which allowed the tags' attachment to be manually checked on a weekly basis by grasping the tag and attempting to move it. Nearing the molt, tags were checked on a daily basis. The animals were routinely fed twice daily and food totals and caloric intake recorded for each feeding. Weights of the subject animals were collected opportunistically or in conjunction with routine physical examinations. Trends in dietary intake and animal weights were compared to an untagged conspecific adult male in the same system. Blood was collected for routine health screening from each animal at the start and at 2 additional times during the present study, and full hematology and serum chemistry panels were evaluated.

\section{RESULTS}

The dummy tags were attached on 28 October 2003. Tag 1 (no mesh) fell off on 23 June 2004 and Tag 2 (with mesh) fell off on 22 June 2004. Neither of the tag attachments was found to have loosened throughout the present study. The tag placed directly on the pelage started to loosen $\sim 6 \mathrm{~d}$ before animal care staff began to notice hair loss characteristic of molting; the 
tag completely detached and fell off the animal $2 \mathrm{~d}$ into the visible molt. (Fig. 1). No skin irritation was noted and a new coat was growing in beneath the tag. The tag placed with the mesh layer started to loosen $\sim 7 \mathrm{~d}$ before the molt. The tag fell off $2 \mathrm{~d}$ before the visible onset of the molt and, similar to the no-mesh tag, a new pelage layer was found at the attachment site. The mesh-epoxy layer developed a crack a few months into the present study, and when the tag eventually fell off there was a small area of mild skin irritation under the cracked area, presumably where there had been rubbing of the hard epoxy-mesh layer against the skin. At the time of detachment the irritation was minor and did not break the skin surface or produce any reaction from the animal when the area was touched. Parts of the mesh remained attached to the animal for a few days after the tag had fallen off (Fig. 2).

No changes in inter- or conspecific behavior with pool mates or normal swimming and haul-out patterns were noted by the husbandry staff for either animal, and both animals continued to station and feed normally throughout the present study. As expected, dietary intake increased throughout the winter and up until the time of the molt (Fig. 3). The body weights of both tagged animals also increased through the study
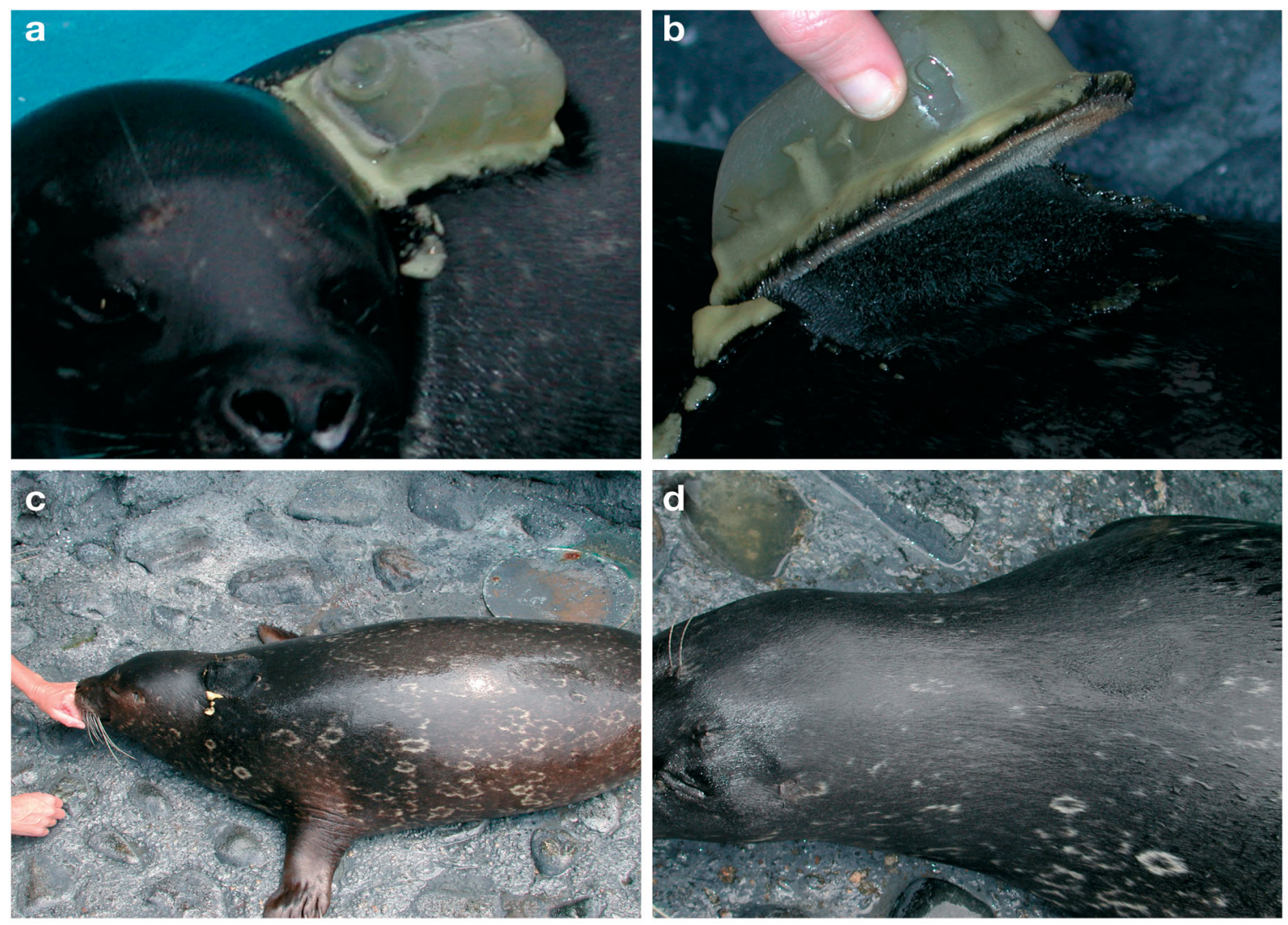

Fig. 1. Phoca vitulina richardsi. Tag placed without mesh layer (a) 5 wk after attachment (1 December 2003), (b) $2 \mathrm{~d}$ before the tag fell off (21 June 2004), (c) 2 d after the tag fell off (25 June 2004), and (d) 2 mo after the tag fell off (20 August 2004) 

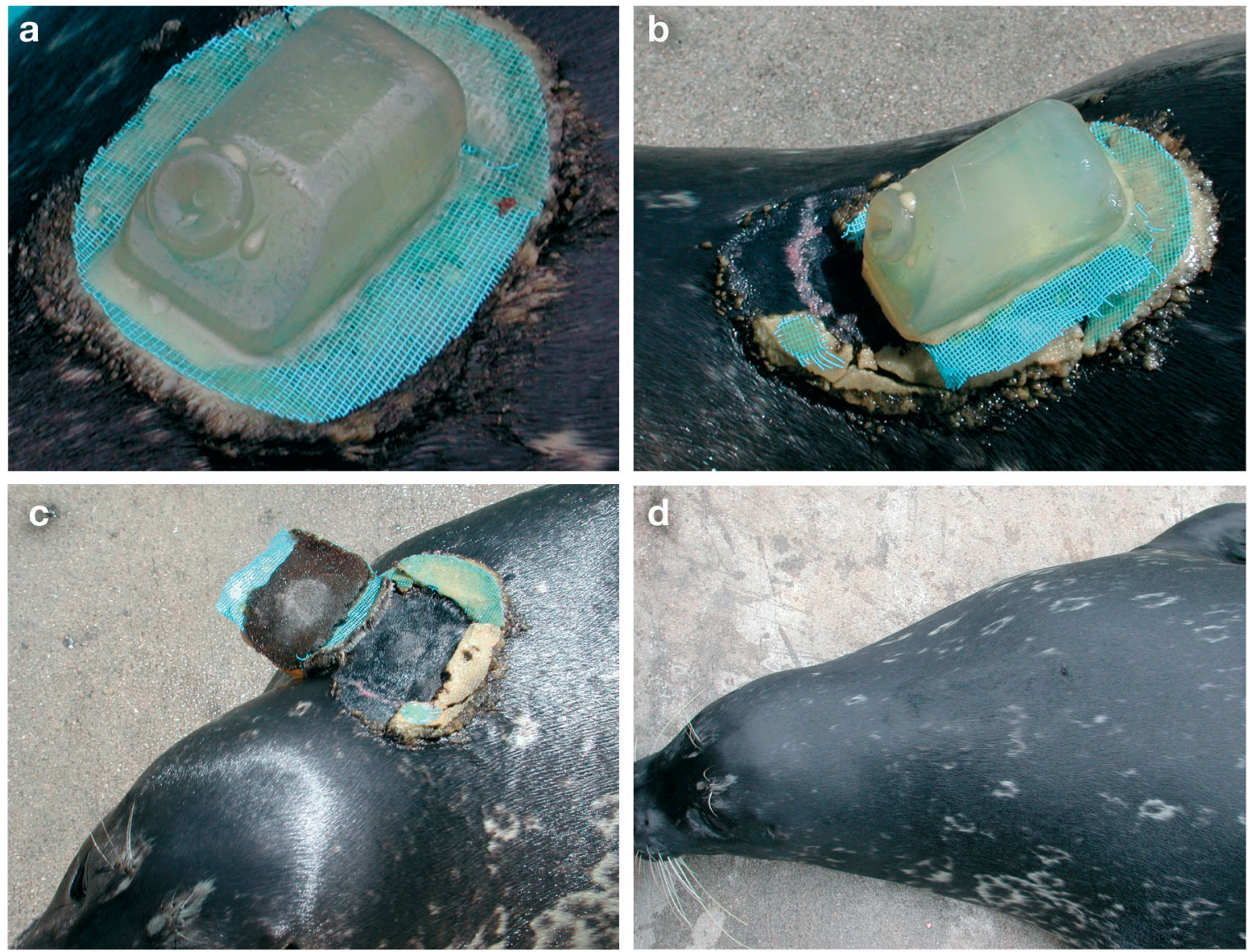

Fig. 2. Phoca vitulina richardsi. Tag placed with a mesh layer (a) 5 wk after attachment (1 December 2003), (b) $2 \mathrm{~d}$ before the tag fell off (20 June 2004), (c) semi-detached tag, 1 d prior to tag falling off, showing a small area of superficial skin irritation (21 June 2004), and (d) 2 mo after the tag fell off (20 August 2004)

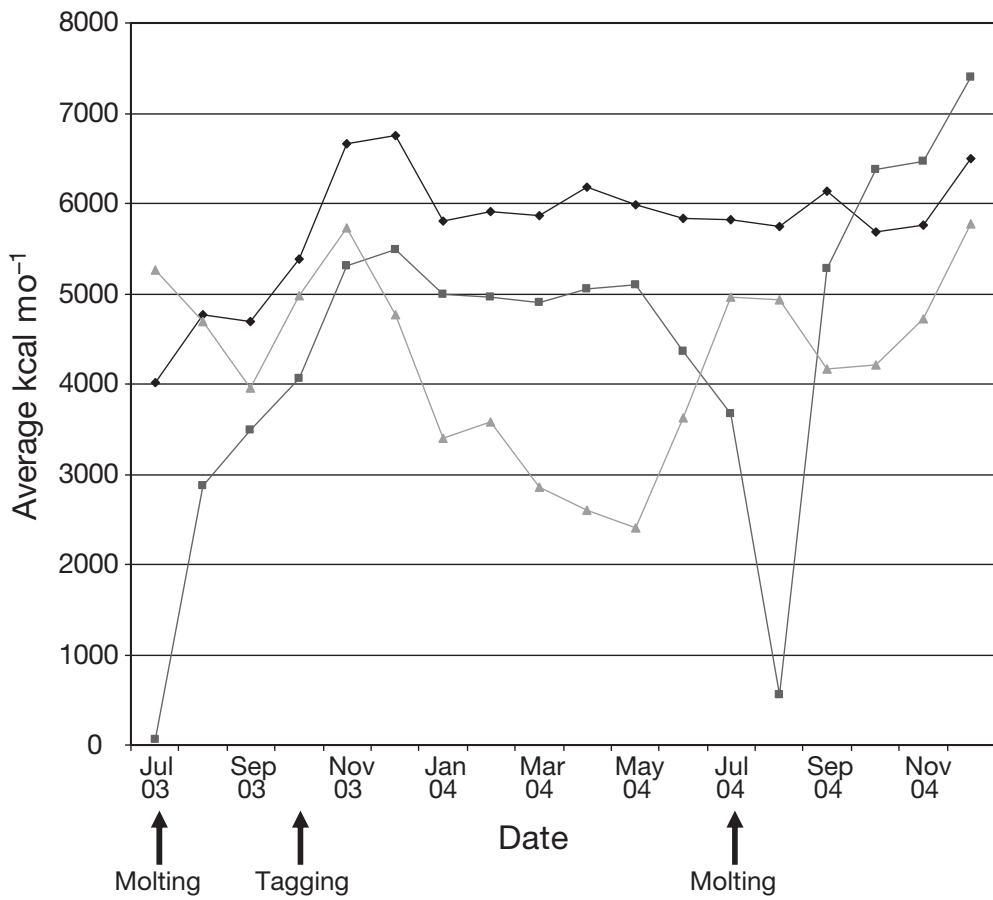

- Study animal 1

- Study animal 2

$\triangle$ Untagged animal

Fig. 3. Phoca vitulina richardsi. Caloric consumption of the 2 study animals and 1 untagged animal from July 2003 to December 2004. Tags were attached 28 October 2003 and molting occurred in July of each year 
chlorinated or ozonated systems being especially prone to damage from glue seem unwarranted in facilities employing modern state-of-the-art disinfecting systems; the subjects in the present study were maintained in such a system, and the attachment of both dummy tags to their pelage lasted, as expected, until the next molt. Minor behavioral changes associated with the presence of the tags were noted only during a short pre-molt period when the tag attachments had loosened.

We noted no difference in the strength or length of tag attachment associated with mesh or no mesh attachment. Although there was some minor skin irritation confined to the small area where the epoxycovered mesh had cracked and rubbed against the animal, this was superficial and did not penetrate the skin (Fig. 2b). Based on this small pilot study, we inferred that 5-minute epoxy works well for satellite tag attachment to small phocids. With only a single sample of each attachment type, we were not able to determine whether the use of a mesh layer offered any special advantages but we did determine that the potential to cause minor skin irritation exists with use of this method. Since we were unable to fully examine the skin beneath the mesh of this animal until its detachment we can only speculate about the severity of any skin irritation during the post cracking period. The animal's behavior was unchanged and manipulation of the tag produced no evidence of discomfort.

The applicability of our experiences and observations in this small pilot study utilizing healthy animals held in a controlled environment to other pinniped species and to tagged animals in the wild can and should be questioned, but in this instance the attachment-detachment process was without significant adverse effect. The dummy tags we employed did not have antennas attached, but whether an attached antenna would have altered the length of attachment or the behavior of the tagged or pool mate seals is conjectural. Although small, the present study allowed monitoring of the animals continuously by animal care and veterinary staff who were familiar with the subjects' specific pretagging behavior and thus able to detect minor changes which would be difficult to monitor in studies in the wild. The subjects' behavior remained essentially unchanged in our controlled and easily observed exhibit environment, despite close contact with numerous other pinnipeds and potential contact with a number of different surfaces and substrate types. The only behavioral changes observed were mild and short-term and occurred at the time of tag detachment. Prior expressed concerns over the applicability of results obtained from use of captive animals in chlorinated and/or ozonated systems were not corroborated. We expect, and encourage others, to repeat the present study with larger numbers and different species of pinnipeds. Since it is not feasible to conduct continous long-term field studies on tagged individuals, only closely observed long-term studies on captive animals will allow us to assure ourselves that the instruments and attachment methods we employ are truly humane and without significant behavioral effects on tagged individuals.

Acknowledgements. The authors thank the Mystic Aquarium \& Institute for Exploration husbandry, veterinary, and research staff members who helped to restrain the seals during the tag attachment and observed them on a daily basis throughout the project. We also thank Wildlife Computers for their generous donation of the dummy tags. The present study was approved as Project 03012 by the Mystic Aquarium \& Institute for Exploration's Institutional Animal Care and Use Committee. This constitutes scientific contribution no. 182 from the Sea Research Foundation.

\section{LITERATURE CITED}

Baker JD, Johanos TC (2002) Effects of research handling on the endangered Hawaiian monk seals. Mar Mamm Sci 18:500-512

Bengtson JL (1993) Telemetry and electronic technology. In: Laws RM (ed) Antarctic seals: research methods and techniques. Cambridge University Press, Cambridge, p 119-139

Burns JM, Castellini MA, Testa JW (1999) Movements and diving behavior of weaned Weddell seal (Leptonychotes weddellii) pups. Polar Biol 21:23-36

Early G, Cooper R, Kraus S, Williamson M (1999) The movements and behavior of released rehabilitated seals. 13th Biennal Conf Mar Mamm, Wailea, HI, 28 November-3 December 1999 (Abstract)

Folkow LP, Martensson P, Blix AS (1996) Annual distribution of hooded seals (Cystophora cristata) in the Greenland and Norwegian Seas. Polar Biol 16:179-189

Harvey JT (1991) Survival and behavior of previously captive harbor seals after release into the wild. In: Reynolds JE, Odell KD (eds) Marine mammal strandings in the United States. Proc Second Mar Mamm Stranding Workshop. NOAA Tech Rep NMFS 98:117-122

Jay CV, Garner GW (2002) Performance of a satellite-linked GPS on Pacific walruses (Odobenus rosmarus divergens). Polar Biol 25:235-237

Jeffries SJ, Brown RF, Harvey JT (1993) Techniques for capturing, handling and marking harbour seals. Aquat Mamm 19:21-25

Lander ME, Westgate AJ, Bonde RK, Murray MJ (2001) Tagging and tracking. In: Dierauf LA, Gulland FMD (eds) CRC handbook of marine mammal medicine, 2nd edn. CRC Press, Boca Raton, FL, p 851-880

> LeBoeuf BJ, Crocker DE, Costa DP, Blackwell SB, Webb PM, Houser DS (2000) Foraging ecology of northern elephant seals. Ecol Monogr 70:353-382

> Lowry LF, Frost KJ, Davis R, DeMaster DP, Suydam RS (1998) Movements and behavior of satellite-tagged spotted seals (Phoca largha) in the Bering and Chukchi Seas. Polar Biol 19:221-230

> Matthiopoulos J, McConnell B, Duck C, Fedak M (2004) Using satellite telemetry and aerial counts to estimate space use by grey seals around the British Isles. J Appl Ecol 41:476-491

> McMahon CR, Field IC, Bradshaw CJA, White GC, Hindell MA (2008) Tracking and data-logging devices attached to elephant seals do not affect individual mass gain or survival. J Exp Mar Biol Ecol 360:71-770

Submitted: October 17, 2008; Accepted: February 13, 2009

Proofs received from author(s): May 12, 2009 